\title{
Bi-directional relationships between body mass index and height from three to seven years of age: an analysis of children in the United Kingdom Millennium Cohort Study
}

\author{
Laia Bécares University of Manchester, UK \\ Yvonne Kelly University College London, UK \\ Scott Montgomery Örebro University, Sweden \\ Amanda Sacker University College London, UK, \\ a.sacker@ucl.ac.uk
}

(Received January 2015 Revised September 2015)

http://dx.doi.org/10.14301/Ilcs.v7i1.339

\section{Abstract}

Adiposity and height are known to correlate in childhood but it is less clear whether height and weight gain occur in synergy. We investigate the bidirectional relationships between measures of height and body mass index (BMI) - an indicator of adiposity - and their rates of change. The sample comprises singleton children in the Millennium Cohort Study $(N=11,357)$. Child anthropometrics measured by trained interviewers at ages three, five and seven years (20032009) were transformed to standardised scores based on 1990 British Growth Reference data from which piecewise linear models for height and BMI were jointly fitted. At three years of age, $z$ Height was positively related to subsequent $Z B M I$ velocities, whereas $z B M I$ at three years was positively related to zHeight velocity to age five but inversely related to $z$ Height velocity from five to seven years of age. Age three $z B M I$ predicted zHeight velocity from three to five years more strongly than age three zHeight predicted $z B M I$ velocity over the same period. The rate of change in zHeight was positively correlated with subsequent $z B M I$ velocity and vice versa. This new evidence on the bidirectional relationships between height and BMI velocities sheds light on the early childhood origins of obesity in adulthood and the need to monitor growth as well as weight gain.

\section{Keywords}

Body mass index, child growth, height, Millennium Cohort Study, United Kingdom

\section{Introduction}

It has long been known that a high degree of adiposity (an excessive accumulation of fat) and height are positively correlated in childhood (Hanks, Newton \& Casazza, 2013; Lloyd, Wolff \& Whelen, 1961; Samani-Radia \& McCarthy, 2011; Wolff, 1955). Children who are taller with a higher body mass index (BMI) - signalling greater adiposity - in childhood have an earlier puberty followed by a slower than average rate of change in height in adolescence (He, He \& Karlberg, 2001). This is said to account for the paradoxical positive correlation between height and BMI in childhood but a negative correlation in adulthood (Bosy-Westphal, Plachta-Danielzik, Doerhoefer \& Mueller, 2009).

Growth in childhood is affected by many factors including genetics, hormones and nutrition (Fischbein \& Pedersen, 1986; Forbes, 1977; Hindmarsh, Smith, Brook \& Matthews, 1987). 
Childhood obesity tracks into adulthood (Baird, et al., 2005; Serdula, et al., 1993), and is associated with an increased risk of adult morbidity and mortality (Must, Jacques, Dallal, Bajema \& Dietz, 1992; Reilly \& Kelly, 2011). Genetic markers of adult obesity have been associated with metabolism (Pearce, et al., 2013), with children's satiety and food intake (Cecil, Tavendale, Watt, Hetherington \& Palmer, 2008; Wardle, et al., 2008), and have been linked with height and weight velocities in infancy (Elks, et al., 2010). These associations suggest that associated metabolic and/or appetitive characteristics result in more free energy that is used either for growth or stored as adipose tissue. Consequently, the temporality of rapid growth and accumulation of adiposity will depend in part on available energy and the growth phase of the child. As adipose tissue is an energy store, its accumulation also signals energy available for height-related growth (Wells, 2012).

Although height-related growth follows a relatively predictable path, the transition periods between growth phases (infantile, childhood, juvenile) are sensitive windows of developmental plasticity when metabolic and environmental factors are most influential (Hochberg, 2011).The prevalence of overweight across height quintiles has been found to increase ten-fold from three to ten years of age (Freedman, et al., 2004) suggesting synergy between adiposity and height as children mature. Longitudinally height is positively associated with higher obesity risk: pre-school children initially tall for their age were more likely to be obese at nine year follow-up (Stanojevic, Kain \& Uauy, 2007). Studies also find BMI is associated with height velocity, as children's increased BMI preceded advancements in skeletal development and subsequent tall stature (Johnson, et al., 2012) and height velocities between eight and 18 years are predicted by changes in BMI from two to eight years of age (He, et al., 2001).

Longitudinal studies offer the potential to disentangle the relationship between height and adiposity, but to our knowledge, no study has investigated relationships between height and adiposity indicated by $\mathrm{BMI}$ and rates of change simultaneously. This study examines the bidirectional relationships between height and $\mathrm{BMI}$ z-scores (zHeight and zBMI, hereafter) from ages three to seven years old in a large population-based study of young children in the United Kingdom (UK).
We hypothesise that i) as zBMI and zHeight are markers of the availability of free energy through over-nutrition, zHeight and zBMI will correlate positively with zBMI velocity and zHeight velocity; ii) zBMI will correlate more strongly with zHeight velocity than zHeight will correlate with $z B M I$ velocity as $z B M I$ is a more reliable indicator of the availability of energy stored in adipose tissue; and iii) zBMI velocity and zHeight velocity will correlate negatively within the same time period and positively across time periods as energy usage is directed towards increasing height and laying down fat in turn.

\section{Methods \\ Data}

The Millennium Cohort Study (MCS) is a nationally representative longitudinal study of infants born in the UK between September 2000 and January 2002. Families with children who were living in the UK at age nine months were identified through the Department of Work and Pensions Child Benefit system and selected on the basis of where the family was resident shortly after the time of birth. The sample is clustered at the electoral ward (an administrative unit level) such that disadvantaged areas and areas with a high proportion of ethnic minorities are overrepresented. More detail on the survey design, recruitment and fieldwork are found elsewhere (Hansen, 2012)

There have been survey sweeps when cohort members were aged about nine months (MCS1), three (MCS2), five (MCS3), seven (MCS4), and 11 years (MCS5). At MCS1, 18,552 families were recruited to the study ( $85 \%$ interview rate). At MCS2 a further 692 families joined the survey, but there were 3,655 unproductive interviews, giving a total of 15,589 (81\%). At MCS3 15,246 families $(79.2 \%)$ and at MCS4 13857 families (72\%) were interviewed. This study uses data from MCS2 to MCS4, and successively excluded cohort members if they dropped out of the study before MCS2 $(n=1798)$, were not in the study at MCS4 $(n=3,403)$, were not singletons $(n=360)$, had missing covariate data $(n=710)$ or anthropometric measurement dates were unknown $(n=1,648)$, resulting in an analysis sample comprising 11,357 cohort members (range 11,192 to 11,357 for individual models).

Ethical approval for the MCS was obtained from the relevant ethics committees and parents gave 
informed consent before interviews took place, and separate written consent for anthropometric measurements.

\section{Measures}

Anthropometric measures, including weight, height, waist circumference and \%fat, were taken by trained interviewers. The children were weighed without shoes or outdoor clothes using Tanita HD305 scales in MCS2 and MCS3 (Tanita UK Ltd, Middlesex, UK), recorded to the nearest $0.1 \mathrm{~kg}$. Weight and body fat in MCS4 was measured using Tanita BF-522W scales. Height was measured using Leicester Height Measure Stadiometers (Seca Ltd, Birmingham, UK), recorded to the nearest $0.1 \mathrm{~cm}$. For MCS2 and MCS3, we replaced missing height and weight measures with data taken from the Personal Child Health Record $(n<50)$ (Walton, Bedford \& Dezateux, 2006) In MCS3 and MCS4, waist circumference was measured twice to the nearest completed millimetre on bare skin or over light clothing, using a non-elasticated SECA tape (SECA, Hamburg, Germany) positioned horizontally midway between the costal margin and the iliac crest. If the difference between the two measurements was $\geq 2$ $\mathrm{cm}$, a third measurement was taken; the mean of the two closest measures was used. BMI $\left(\mathrm{kg} / \mathrm{m}^{2}\right)$ was calculated from the height and weight measures after conversion to metric scales where necessary. Child anthropometrics were transformed to standardised scores with the LMS method using 1990 British Growth Reference data (Cole, 1990) Measurement dates were used to derive age at measurement in months.

Growth in height and weight is affected by sex, birth weight, household income and ethnicity (Sacker \& Kelly, 2012; Saxena, Ambler, Cole \& Majeed, 2004) and measures of these were included in statistical models. Birth weight in kilograms was collected from the main respondent at first contact (MCS1 or MCS2 for participants new to the study). Household income was measured at each age and equivalised using the modified OECD scale to account for the number of people in the household (Hansen, 2012) and log transformed. Ethnicity was grouped into White British, Indian, Pakistani, Bangladeshi, Black Caribbean, Black African and Other.

\section{Analysis}

To examine the bidirectional relationships between standardised height scores (zHeight) and standardised BMI scores (zBMI) from ages three to seven, we use piecewise latent growth curve models, an extension of latent growth curves that model nonlinear relations over time by using two or more linear piecewise splines. We set the knot at age five after sensitivity analysis comparing competing models with the knot at the MCS3 mean age (5.2 years), and above the mean age (5.4 years) showed placement of the knot did not affect results.

We jointly model zHeight and zBMI by fitting two piecewise linear models with individually-varying times of observation and two linear slope factors to describe trajectories of change in zHeight and zBMI occurring over two time periods (from age three to five, and from age five to seven). Intercepts and slopes are treated as random variables and allowed to covary. The models included adjustment for birth weight, ethnicity and income and were estimated separately for boys and girls. All equations are provided in the online supplementary material.

Piecewise growth curve models were estimated in Mplus version 7.2 using the full-information robust maximum likelihood (MLR) estimator that adjusts for non-response assuming data are missing at random and produces standard errors robust to nonnormality and the non-independence of observations. Analyses take account of the stratified, clustered sample design and are weighted to account for the unequal probability of being sampled.

To ease interpretation we present correlation coefficients and standard errors (SE) between zHeight and zBMI, as well as between baseline measures and growth over time for each individual measure. The correlation coefficients were calculated using the Mplus "Model Constraint: New" option, allowing their standard errors to be estimated using the formula in Kendal and Stuart (1977 p247). All model estimates are presented in the online supplementary material. Because data on waist circumference (zWaist) and \%fat are not available at all ages, reduced forms of the $\mathrm{ZBMI}$ models are estimated and available in online supplementary material.

\section{Results}

Table 1 shows the available anthropometric data at ages three, five and seven years in the MCS. Mean values at each age are presented in their original metric and where appropriate in standard deviate scores. Table 2 breaks down these data further for the growth trajectories sample, showing mean zHeight and zBMI by each covariate, confirming relationships reported elsewhere. 
Table 1. Anthropometrics at three, five and seven in the MCS

\begin{tabular}{|c|c|c|c|c|c|c|}
\hline & \multicolumn{2}{|c|}{ Age three } & \multicolumn{2}{|c|}{ Age five } & \multicolumn{2}{|c|}{ Age seven } \\
\hline & Raw & Standardised $^{1}$ & Raw & Standardised $^{1}$ & Raw & Standardised ${ }^{1}$ \\
\hline \multicolumn{7}{|l|}{ Boys } \\
\hline Height (cm) & 95.48 & 0.00 & 109.62 & 0.02 & 122.68 & 0.14 \\
\hline Weight (kg) & 15.56 & 0.40 & 19.70 & 0.35 & 24.79 & 0.37 \\
\hline BMI $\left(\mathrm{kg} / \mathrm{m}^{2}\right)$ & 17.03 & 0.55 & 16.35 & 0.48 & 16.39 & 0.40 \\
\hline Waist (cm) & $\mathrm{n} / \mathrm{a}$ & $\mathrm{n} / \mathrm{a}$ & 53.46 & 0.49 & 56.52 & 0.70 \\
\hline$\% f_{a t}{ }^{2}$ & $\mathrm{n} / \mathrm{a}$ & $\mathrm{n} / \mathrm{a}$ & $\mathrm{n} / \mathrm{a}$ & $\mathrm{n} / \mathrm{a}$ & 20.02 & $\mathrm{n} / \mathrm{a}$ \\
\hline \multicolumn{7}{|l|}{ Girls } \\
\hline Height (cm) & 94.26 & -0.07 & 108.78 & -0.02 & 121.88 & 0.10 \\
\hline Weight (kg) & 14.83 & 0.29 & 19.36 & 0.28 & 24.69 & 0.28 \\
\hline BMI $\left(\mathrm{kg} / \mathrm{m}^{2}\right)$ & 16.66 & 0.46 & 16.30 & 0.40 & 16.53 & 0.31 \\
\hline Waist (cm) & $\mathrm{n} / \mathrm{a}$ & $\mathrm{n} / \mathrm{a}$ & 53.43 & 0.63 & 56.62 & 0.73 \\
\hline$\% f_{a t}{ }^{2}$ & $\mathrm{n} / \mathrm{a}$ & $\mathrm{n} / \mathrm{a}$ & $\mathrm{n} / \mathrm{a}$ & $\mathrm{n} / \mathrm{a}$ & 22.16 & $\mathrm{n} / \mathrm{a}$ \\
\hline
\end{tabular}

${ }^{1}$ Standard deviate scores derived using LMS standardisation (Cole, 1990)

${ }^{2}$ Total fat mass/total body mass

\section{zHeight and zBMI growth trajectories}

The modelled conditional growth trajectories of zHeight for boys and girls are shown in figure 1. Detailed model estimates are given in online supplementary tables S1 (boys) and S2 (girls). Boys were taller than girls, although both sexes followed similar trajectories of increased zHeight with age and acceleration in zHeight after age five. Baseline zHeight was not significantly related to change between three and five years (Tables 3 and 4, top left quadrant), but was inversely correlated with change between five and seven years, so that children who were taller at age three grew more slowly after five years of age (boys $r=-0.06, \mathrm{SE}=$ 0.03 ; girls $r=-0.12, \mathrm{SE}=0.04$ ). Height velocity from three to five years was inversely correlated with height velocity from five to seven years, although this was only significant for girls (boys $r=-0.20, \mathrm{SE}=0.14$; girls $r=$ $-0.29, \mathrm{SE}=0.15$ ).

The conditional growth trajectories of $\mathrm{zBMI}$ for boys and girls (figure 1 ) show that boys had higher zBMI than girls, with both following similar trajectories of decreased zBMI with age. The rate that $\mathrm{zBMI}$ decreased accelerated somewhat after age five. Baseline $\mathrm{zBMI}$ measures were inversely correlated with changes over time (tables 3 and 4 , bottom right quadrant): Children with higher zBMI at age three had a greater decline in zBMI from age three to five (boys $r=-0.28, \mathrm{SE}=0.14$; girls $r=-0.29$, $\mathrm{SE}=0.14)$ and boys had a greater decline from age five to age seven $(r=-0.11$, SE 0.04). 
Table 2. Mean (95\% confidence intervals) of zHeight and zBMI at three, five and seven years by covariate values for 11,357 children in the MCS

\begin{tabular}{|c|c|c|c|c|c|c|c|}
\hline & \multirow[b]{2}{*}{$N(\%)^{1}$} & \multicolumn{2}{|c|}{ Age 3 years } & \multicolumn{2}{|c|}{ Age 5 years } & \multicolumn{2}{|c|}{ Age 7 years } \\
\hline & & zHeight & zBMI & zHeight & zBMI & zHeight & zBMI \\
\hline \multicolumn{8}{|l|}{ Sex } \\
\hline Male & $5717(51)$ & $0.02(-0.02,0.06)$ & $0.56(0.52,0.60)$ & $0.04(0.00,0.07)$ & $0.49(0.45,0.53)$ & $0.16(0.12,0.20)$ & $(0.39(0.35,0.43)$ \\
\hline Female & $5640(49)$ & $-0.07(-0.11,-0.04)$ & $0.47(0.44,0.50)$ & $-0.02(-0.06,0.01)$ & $0.40(0.37,0.43)$ & $0.10(0.06,0.14)$ & $0.31(0.28,0.35)$ \\
\hline \multicolumn{8}{|l|}{ Ethnicity } \\
\hline White British & $9703(87)$ & $-0.05(-0.08,-0.03)$ & $0.55(0.52,0.58)$ & $-0.02(-0.05,0.01)$ & $0.47(0.45,0.50)$ & $0.11(0.08,0.14)$ & $0.36(0.34,0.39)$ \\
\hline Indian & $298(2)$ & $0.16(-0.04,0.36)$ & $-0.09(-0.28,0.10)$ & $0.20(0.01,0.38)$ & $0.00(-0.23,0.23)$ & $0.30(0.12,0.49)$ & $0.14(-0.07,0.34)$ \\
\hline Pakistani & $483(3)$ & $0.10(0.00,0.19)$ & $0.12(-0.02,0.25)$ & $0.09(0.01,0.17)$ & $0.12(-0.06,0.29)$ & $0.14(0.04,0.24)$ & $0.04(-0.12,0.19)$ \\
\hline Bangladeshi & $171(1)$ & $-0.05(-0.28,0.18)$ & $0.21(-0.18,0.60)$ & $-0.02(-0.27,0.22)$ & $0.23(-0.04,0.50)$ & $-0.03(-0.29,0.23)$ & $0.24(-0.03,0.51)$ \\
\hline Black Caribbean & $225(2)$ & $0.12(-0.03,0.28)$ & $0.67(0.46,0.88)$ & $0.23(0.08,0.38)$ & $0.59(0.39,0.79)$ & $0.35(0.20,0.51)$ & $0.60(0.40,0.80)$ \\
\hline Black African & $215(2)$ & $0.80(0.64,0.95)$ & $0.62(0.41,0.84)$ & $0.80(0.67,0.93)$ & $0.67(0.48,0.87)$ & $0.85(0.68,1.02)$ & $0.72(0.50,0.94)$ \\
\hline Other & $262(2)$ & $-0.14(-0.29,0.02)$ & $0.26(0.08,0.43)$ & $-0.09(-0.26,0.08)$ & $0.19(0.01,0.37)$ & $0.03(-0.13,0.19)$ & $0.09(-0.11,0.29)$ \\
\hline \multicolumn{8}{|l|}{ Birth weight } \\
\hline$\geq 2500 \mathrm{~g}$ & $10668(94)$ & $0.00(-0.02,0.03)$ & $0.54(0.51,0.57)$ & $0.03(0.01,0.06)$ & $0.47(0.44,0.50)$ & $0.15(0.13,0.18)$ & $0.37(0.34,0.40)$ \\
\hline$<2500 \mathrm{~g}$ & $689(6)$ & $-0.50(-0.60,-0.39)$ & $0.10(-0.02,0.21)$ & $-0.42(-0.52,-0.32)$ & $0.07(-0.04,0.17)$ & $-0.26(-0.36,-0.15)$ & $0.05(-0.05,0.15)$ \\
\hline \multicolumn{8}{|l|}{ Income (age 3) } \\
\hline$>60 \%$ median & $8625(76)$ & $0.00(-0.03,0.03)$ & $0.53(0.50,0.56)$ & & & & \\
\hline$\leq 60 \%$ median & $2732(24)$ & $-0.12(-0.17,-0.07)$ & $0.48(0.41,0.55)$ & & & & \\
\hline \multicolumn{8}{|l|}{ Income (age 5) } \\
\hline$>60 \%$ median & $8724(76)$ & & & $0.04(0.01,0.07)$ & $0.52(0.50,0.55)$ & & \\
\hline$\leq 60 \%$ median & $2633(24)$ & & & $-0.10(-0.16,-0.04)$ & $0.48(0.41,0.55)$ & & \\
\hline \multicolumn{8}{|l|}{ Income (age 7) } \\
\hline$>60 \%$ median & $8639(77)$ & & & & & $0.16(0.13,0.19)$ & $0.53(0.50,0.56)$ \\
\hline$\leq 60 \%$ median & $2718(23)$ & & & & & $0.01(-0.04,0.07)$ & $0.47(0.41,0.53)$ \\
\hline
\end{tabular}

\footnotetext{
${ }^{1}$ unweighted sample size; weighted percentage
} 
Figure 1. zHeight and $\mathrm{zBMI}$ growth trajectories for boys and girls in the UK Millennium Cohort Study (2003-2009)

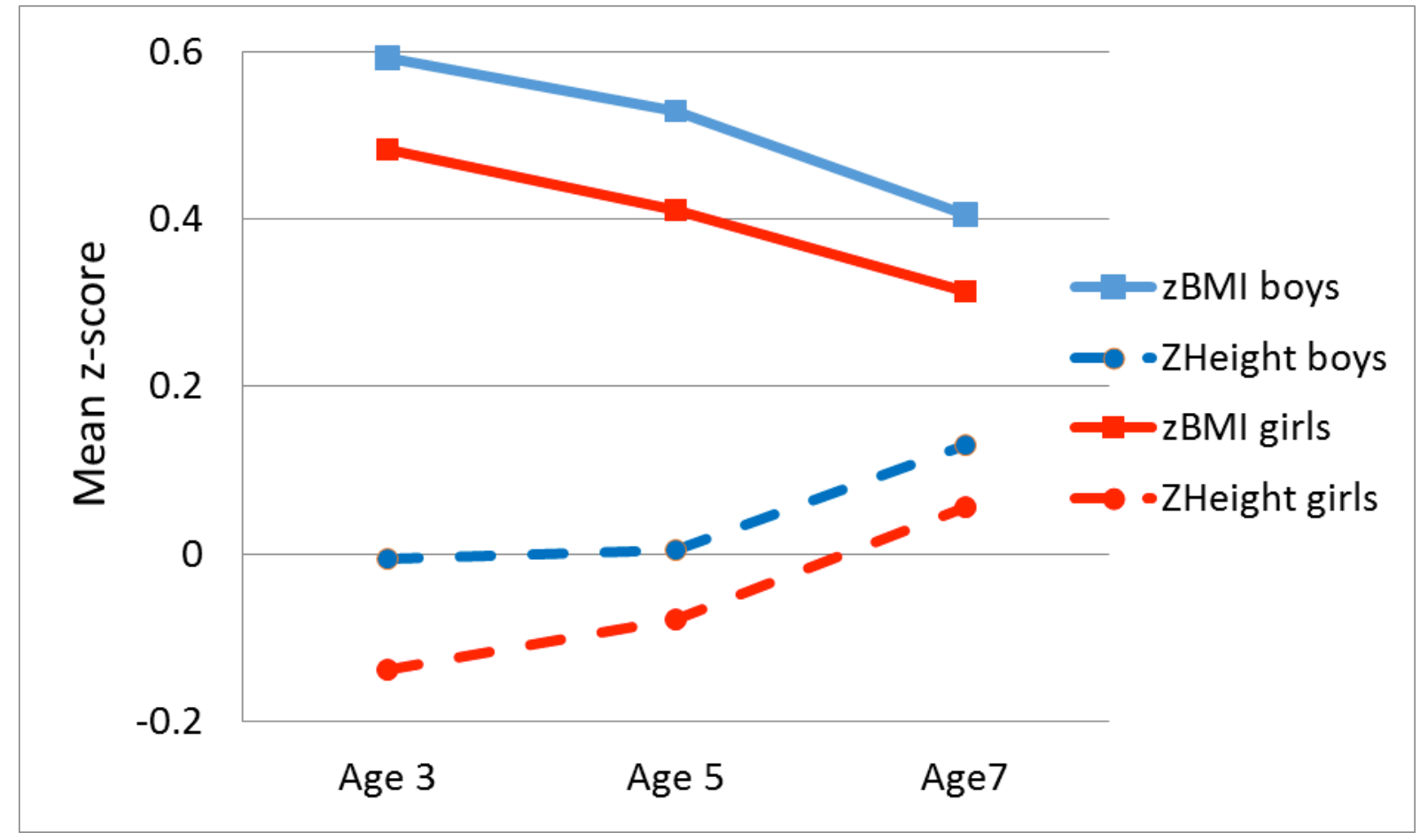

zHeight and zBMI expressed in standard deviate scores derived using LMS standardisation (Cole, 1990)

Table 3. Correlations (standard errors) between baseline zHeight and $\mathrm{zBMI}^{1}$ and changes over time for 5,717 boys in the MCS

\begin{tabular}{lllllll}
\hline & zHeight 3 & zHeight 3-5 & zHeight 5-7 & zBMI 3 & zBMI 3-5 & zBMI 5-7 \\
\hline $\begin{array}{l}\text { zHeight } \\
\text { 3 years }\end{array}$ & 1.00 & & & & \\
zHeight & -0.07 & 1.00 & & & \\
3-5 years & $(0.09)$ & & & & \\
zHeight & $-0.06^{*}$ & -0.20 & 1.00 & & \\
5-7 years & $(0.03)$ & $(0.14)$ & & & \\
zBMI & -0.00 & $0.40^{* * *}$ & $-0.06^{*}$ & 1.00 & \\
3 years & $(0.03)$ & $(0.07)$ & $(0.03)$ & & \\
zBMI & $0.24^{* * *}$ & $-0.66^{* * *}$ & $0.43^{* * *}$ & $-0.28^{*}$ & 1.00 & \\
3-5 years & $(0.04)$ & $(0.13)$ & $(0.09)$ & $(0.14)$ & \\
zBMI & 0.07 & $0.57^{* * *}$ & $-0.46^{* * *}$ & $-0.11^{* *}$ & -0.16 & \\
5-7 years & $(0.04)$ & $(0.17)$ & $(0.14)$ & $(0.04)$ & $(0.21)$ & \\
\hline
\end{tabular}

$* P<0.05, * * P<0.01, * * * P<0.001$

${ }^{1}$ zHeight and zBMI expressed in standard deviate scores derived using LMS standardisation (Cole, 1990) 
Table 4. Correlations (standard errors) between baseline zHeight and $\mathrm{zBMI}^{1}$ and changes over time for 5,640 girls in the MCS

\begin{tabular}{lllllll}
\hline & zHeight 3 & zHeight 3-5 & zHeight 5-7 & zBMI 3 & zBMI 3-5 & zBMI 5-7 \\
\hline $\begin{array}{l}\text { zHeight } \\
\text { 3 years }\end{array}$ & 1.00 & & & & \\
zHeight & 0.70 & 1.00 & & & \\
3-5 years & $(0.12)$ & & & \\
zHeight & $-0.12^{* * *}$ & $-0.29 *$ & 1.00 & & \\
5-7 years & $(0.04)$ & $(0.15)$ & & & \\
zBMI & $0.06^{* *}$ & $0.40^{* * *}$ & $-0.10^{* *}$ & 1.00 & \\
3 years & $(0.03)$ & $(0.09)$ & $(0.04)$ & & \\
zBMI & $0.19^{* * *}$ & $-0.63^{* * *}$ & $0.61^{* * *}$ & $-0.29 *$ & 1.00 & \\
3-5 years & $(0.04)$ & $(0.19)$ & $(0.20)$ & $(0.14)$ & \\
zBMI & 0.17 & 0.65 & -0.37 & -0.04 & -0.13 & \\
5-7 years & $(0.11)$ & $(0.52)$ & $(0.33)$ & $(0.05)$ & $(0.20)$ & \\
\hline
\end{tabular}

$* P<0.05,{ }^{* *} P<0.01, * * * P<0.001$

${ }^{1}$ zHeight and zBMI expressed in standard deviate scores derived using LMS standardisation (Cole, 1990)

\section{Relationship between height and BMI growth trajectories}

There was a significant correlation between baseline zHeight and zBMI at age 3 for girls only, conditional on ethnicity, birth weight and household income. There was evidence linking zHeight to subsequent zBMI velocities: The correlation between zHeight at age three and zBMI velocity between ages three to five was 0.24 (SE = $0.04, P<0.0005$, Table 3 ) for boys and 0.19 (SE $=$ $0.04, P<0.0005$, Table 4) for girls. The correlation between zHeight at age three and zBMI velocity between ages five to seven was weaker and of marginal significance for boys $(r=0.07, \mathrm{SE}=0.04 ; P$ $=0.05$ ). For girls, the correlation was stronger but imprecisely estimated $(r=0.17, \mathrm{SE}=0.11)$.

Examining correlations between baseline BMI and height velocities, we find that higher $\mathrm{zBMI}$ at age three was positively correlated with increased zHeight gain from age three to five; children who were fatter at age three grew taller between ages three and five. The strength of the correlation between baseline $\mathrm{zBMI}$ and zHeight velocity was about twice that between baseline zHeight and zBMI velocity (boys: $r=0.40$ versus 0.24 ; girls: $r=$ 0.40 versus 0.19 ), a significant difference (boys: $\Delta r=$ $0.16, P=0.02$; girls: $\Delta r=0.22, P=0.01$ ). However, the correlation reversed direction between ages five to seven, whereby children who were fatter at age three grew more slowly later.

Increased zHeight between ages three and five was correlated with increased $\mathrm{zBMI}$ in the next time period. Boys who grew taller more quickly between ages three and five put on more weight from ages five to seven. The relationship was stronger but imprecisely estimated for girls. There was also a positive correlation between $\mathrm{zBMI}$ velocity from three to five years and $z$ Height velocity from five to seven years (again stronger for girls), such that children who put on more weight between ages three to five, grew taller at a faster rate thereafter.

Analyses of the growth trajectories between height, waist and \%fat present additional support for the interrelation between height and adiposity. Baseline $z W a i s t$ was not related to $z W a i s t$ velocity subsequently (Online supplementary tables S3 and S4). Results show that taller zHeight at age three was correlated with higher $z$ Waist at age five and $\%$ fat measured at age seven in both boys and girls. There was weak evidence $(P<0.10)$ that higher zHeight velocity to age five was positively correlated with higher $z$ Waist at age five in girls and that higher zHeight velocity from five to seven years was positively correlated with higher zWaist 
velocity over the same period in boys. The evidence was stronger that zHeight velocities to age five were positively correlated with \%fat at age seven (online supplementary tables S5 and S6).

\section{Discussion}

In a large representative sample of UK children, the relationship between zHeight and zBMI in childhood was dynamic and bidirectional. Our first hypothesis was partially supported by evidence showing zHeight at three years of age to be positively correlated with subsequent zBMI velocities and $\mathrm{zBMI}$ at three years positively correlated with zHeight velocity to age five. However, zBMI at three was inversely correlated with zHeight velocity from five to seven years of age. Consistent with our second hypothesis, the longitudinal relationship between $\mathrm{zBMI}$ and zHeight velocity from three to five years was stronger than that between zHeight and $\mathrm{zBMI}$ velocity over the same period. In support of the third hypothesis, zHeight velocity from three to five years was negatively correlated with $\mathrm{zBMI}$ velocity over the same age range and positively correlated with subsequent zBMI velocity, and vice versa for associations of $\mathrm{zBMI}$ velocity from three to five years with zHeight velocity from three to five years and from five to seven years.

Strengths of the study are the large representative sample and the use of objectively measured anthropometric data. Previous studies have cautioned against using parental reports of their child's height and weight as this may bias results (Brettschneider, Ellert \& Schaffrath Rosario, 2012; Weden, et al., 2013). The present study has simultaneously modelled bidirectional longitudinal associations between zHeight and zBMI, overcoming some of the limitations of previous work that assumed a unidirectional relationship. Some weaknesses must be acknowledged. Data on the children were only taken at three time points, preventing us from modelling changes with a parametric non-linear function. More frequent measurements would have also allowed us to detect onsets of rebound or growth spurts. We made an assumption about the position of the knot for the piecewise linear models. For simplicity we modelled the knot at five years of age; however sensitivity analyses with alternative knot positions did not reveal any differences to our findings. We had no information on length at birth although birth weight was included as a covariate. $\mathrm{BMI}$ is the most commonly used measure of adiposity, yet its use in childhood has supporters and critics (Metcalf, et al., 2011) and it is influenced by other factors such as muscle mass; although a further strength of the study is that findings based on waist circumference and \%fat corroborate those using zBMI. It is still possible that the findings might differ if growth curve models using other more specific measures of adiposity were estimated (Cole, Faith, Pietrobelli \& Heo, 2005).

We found that, on average in the UK, young children born around the year 2000 were of similar stature to children of the same age used to derive the 1990 British Growth Standards, but they had much higher BMI's. Children in the MCS grew taller than the 1990 standards by age seven, while at the same time differences in BMI slightly narrowed. The secular increases in height and BMI shown here are similar to those from other European Union countries over the same period (Cardoso \& Padez, 2008; Heude, et al., 2003). The present study did not address the question of changing trends. However increases in BMI over such a relatively short period are likely to be a consequence of the free energy available from simultaneous increases in children's energy intake together with decreases in energy expenditure (Anderson \& Butcher, 2006). An alternative suggestion is provided by Buchan, Bundred, Kitchiner and Cole (2007). In their study of time trends in BMI and height, they note the relationship between tall stature and increases in $\mathrm{BMI}$ and hypothesise a role for appetite regulation while at the same time acknowledging that children did not become taller over their period of study.

Although we found baseline zHeight and zBMI to be uncorrelated, zHeight and $z B M I$ were related cross-sectionally at later ages (not shown), similar to the findings of Rolland-Cachera Deheeger, Maillot, and Bellisle,(1982). Our results on the relationship of zHeight and $\mathrm{zBMI}$ with zHeight and zBMI velocities are also consistent with other research (Buchan, et al., 2007; Stanojevic, et al., 2007; Walker, Gaskin, Powell \& Bennett, 2002) but we add new evidence of bidirectional associations between zHeight and $\mathrm{zBMI}$ and that $\mathrm{zBMI}$ predicts zHeight velocity more strongly than zHeight predicts zBMI velocity. Our results are also consistent with longitudinal relationships between height and BMI velocities reported previously (Dietz \& Hartung, 1985; He, et al., 2001; Metcalf, et al., 
2011). Although the correlation between zHeight velocity between ages three and five years and zBMI velocity between ages five and seven years was greater than that between zBMI velocity between ages three and five years and zHeight velocity thereafter, the differences were not significant (boys: $\Delta r=0.14, P=0.23$; girls: $\Delta r=0.04$, $P=0.47$ ).

There was an unexpected inverse correlation of age three $\mathrm{zBMI}$ and $\mathrm{zHeight}$ velocity from five to seven years of age. Studies of the adiposity rebound may offer some insight into this finding. On average, adiposity increases in infancy and then declines followed by a rebound around the age of six years (Rolland-Cachera, Deheeger, Maillot \& Bellisle, 2006). An earlier adiposity rebound is associated with a higher BMI before, during and after the rebound (Freedman, Khan, Serdula, Srinivasan \& Berenson, 2001; Williams, 2005). This phenomenon can be observed in the MCS (see Table 1). If children who have a higher zBMI at age three have an earlier adiposity rebound, then it follows that they could be laying down fat from five to seven years. The free energy hypothesis would predict a resultant diversion from height growth during this phase of development.

There were two instances where the magnitude of correlations were larger for girls than boys but their precision was much weaker, suggesting diversity in girls' synergy between height and adiposity. Both instances involved relationships with zBMI velocity between ages five and seven years. The mechanisms underlying this finding are unknown and warrant further investigation.

These data are of relevance to clinicians concerned with growth or obesity risk in childhood. The evidence from a small clinical study is that height velocity can be slowed down by weight loss (Dietz \& Hartung, 1985). Indeed, Dietz emphasised that obese children's height should be monitored carefully if placed on even a slightly restrictive diet. The interplay, or competition, between height growth and the laying down of adipose tissue that we have shown is considered to represent a physiologically adaptive trait that enables the body to choose between investing energy in growth or saving energy for storage (Ralt, 2007). This competition is observed even under the 'normal' average population level environmental conditions in our study and indicates that alternatives to severe calorie restriction might be advisable during some phases of childhood development.

The findings also have implications for health inequalities in later life. In general, household socioeconomic position (SEP) is inversely related to obesity in childhood (Shrewsbury \& Wardle, 2008). Yet interactions between SEP and height have been observed such that the association between SEP and obesity is greater in taller children (Murasko, 2009). Our longitudinal analysis suggests how high calorie diets might bring about these interactions and contribute to greater social inequalities in obesity in adulthood. Disturbingly, 40-year trends in the US show that BMI and height increases have been greatest in children from more disadvantaged households (Murasko, 2011), and have led to a call for more research on the extent to which these growth-related processes in childhood underlie developmental origins of health disparities (Hanks, et al., 2013). If the trends are mirrored in the UK then we concur with previous suggestions that childhood height for age might help identify children who could become overweight adults (Freedman, Khan, Serdula, Srinivasan, \& Berenson 2001; Navti, Samani-Radia \& McCarthy, 2014), but add that targeting overweight taller children from more disadvantaged homes might prevent health gradients from becoming steeper.

\section{Conclusions}

This study provides evidence on the relationship between height and BMI in early childhood and suggests that clinicians should be made aware that an increase in height velocity, whether rapid catchup in early childhood or disproportionate peripubertal growth, is a marker of an obesogenic environment that may be associated with contemporaneous or future unhealthy weight gain. 


\section{Acknowledgements}

This work was supported by the United Kingdom Economic and Social Research Council grants ES/J019119/1; RES-177-25-0012 and ES/K001582/1. LB was also supported by a Hallsworth Research Fellowship.

The work is based on the United Kingdom Millennium Cohort Study (MCS), which is funded by the United Kingdom Economic and Social Research Council and a consortium of government departments. The original data creators, depositors or copyright holders, the funders of the MCS, and the UK Data Archive bear no responsibility for the accuracy or comprehensiveness of the analyses.

We thank Professor Russell Viner at the Institute of Child Health, University College London, for his helpful comments on the design of the study.

\section{References}

Anderson, P. M., \& Butcher, K. F. (2006). Childhood obesity: trends and potential causes. The Future of children, 16(1), 19-45. http://dx.doi.org/10.1353/foc.2006.0001

Baird, J., Fisher, D., Lucas, P., Kleijnen, J., Roberts, H., \& Law, C. (2005). Being big or growing fast: systematic review of size and growth in infancy and later obesity. BMJ, 331(7522), 929. http://dx.doi.org/10.1136/bmj.38586.411273.E0

Bosy-Westphal, A., Plachta-Danielzik, S., Doerhoefer, R.-P., \& Mueller, M. J. (2009). Short stature and obesity: positive association in adults but inverse association in children and adolescents. British Journal of Nutrition, 102(3), 453-461. http://dx.doi.org/10.1017/S0007114508190304

Brettschneider, A.-K., Ellert, U., \& Schaffrath Rosario, A. (2012). Comparison of BMI Derived from ParentReported Height and Weight with Measured Values: Results from the German KiGGS Study. International Journal of Environmental Research and Public Health, 9(2), 632-647. http://dx.doi.org/10.3390/ijerph9020632

Buchan, I. E., Bundred, P. E., Kitchiner, D. J., \& Cole, T. J. (2007). Body mass index has risen more steeply in tall than in short 3-year olds: serial cross-sectional surveys 1988-2003. International Journal of Obesity, 31(1), 23-29. http://dx.doi.org/10.1038/sj.ijo.0803435

Cardoso, H. F. V., \& Padez, C. (2008). Changes in height, weight, BMI and in the prevalence of obesity among 9-to 11-year-old affluent Portuguese schoolboys, between 1960 and 2000. Annals of Human Biology, 35(6), 624-638. http://dx.doi.org/10.1080/03014460802464200

Cecil, J. E., Tavendale, R., Watt, P., Hetherington, M. M., \& Palmer, C. N. (2008). An obesity-associated FTO gene variant and increased energy intake in children. New England Journal of Medicine, 359(24), 2558-2566. http://dx.doi.org/10.1056/NEJMoa0803839

Cole, T. J. (1990). The LMS method for constructing normalized growth standards. European Journal of Clinical Nutrition, 44, 45-60.

Cole, T. J., Faith, M. S., Pietrobelli, A., \& Heo, M. (2005). What is the best measure of adiposity change in growing children: BMI, BMI \%, BMI z-score or BMI centile? European Journal Clinical Nutrition, 59(3), 419-425. http://dx.doi.org/10.1038/sj.ejcn.1602090

Dietz, W. H., Jr., \& Hartung, R. (1985). Changes in height velocity of obese preadolescents during weight reduction. American Journal of Diseases in Childhood, 139(7), 705-707. http://dx.doi.org/10.1001/archpedi.1985.02140090067031

Elks, C. E., Loos, R. J., Sharp, S. J., Langenberg, C., Ring, S. M., Timpson, N. J., Ness, A. R., Davey Smith, G., Dunger, D. B., Wareham, N. J., \& Ong, K. K. (2010). Genetic markers of adult obesity risk are associated with greater early infancy weight gain and growth. PLoS Medicine, 7(5), e1000284. http://dx.doi.org/10.1371/journal.pmed.1000284

Fischbein, S., \& Pedersen, N. (1986). Multivariate analysis of genetic and environmental influences for longitudinal height and weight data. Acta Geneticae Medicae et Gemellologiae, 36(2), 171-180.

Forbes, G. B. (1977). Nutrition and growth. The Journal of Pediatrics, 91(1), 40-42. http://dx.doi.org/10.1016/S0022-3476(77)80440-X 
Freedman, D. S., Khan, L. K., Serdula, M. K., Dietz, W. H., Srinivasan, S. R., \& Berenson, G. S. (2004). Interrelationships among childhood $\mathrm{BMI}$, childhood height, and adult obesity: the Bogalusa Heart Study. International Journal of Obesity, 28(1), 10-16. http://dx.doi.org/10.1038/sj.ijo.0802544

Freedman, D. S., Khan, L. K., Serdula, M. K., Srinivasan, S. R., \& Berenson, G. S. (2001). BMI rebound, childhood height and obesity among adults: the Bogalusa Heart Study. International Journal of Obesity, 25(4), 543-549. http://dx.doi.org/10.1038/sj.ijo.0801581

Hanks, L. J., Newton, A. L., \& Casazza, K. (2013). Getting to the height of the matter: The relationship between stature and adiposity in pre-pubertal children. Ethnicity \& Disease, 23(1), 71-76.

Hansen, K. (2012). Millennium Cohort Study First, Second, Third and Fourth Surveys: A Guide to the Datasets. (7th ed.). London: Centre for Longitudinal Studies, Institute of Education, University of London.

He, Q., He, J., \& Karlberg. (2001). BMI in Childhood and Its Association with Height Gain, Timing of Puberty, and Final Height. Pediatric Research, 49(2), 244-251. http://dx.doi.org/10.1203/00006450200102000-00019

Heude, B., Lafay, L., Borys, J. M., Thibult, N., Lommez, A., Romon, M., Ducimetiere, P., \& Charles, M. A. (2003). Time trend in height, weight, and obesity prevalence in school children from Northern France, 1992-2000. Diabetes \& Metabolism, 29(3), 235-240. http://dx.doi.org/10.1016/S12623636(07)70032-0

Hindmarsh, P., Smith, P. J., Brook, C. G. D., \& Matthews, D. R. (1987). The relationship between height velocity and growth hormone secretion in short pre-pubertal children. Clinical Endocrinology, 27(5), 581-591. http://dx.doi.org/10.1111/j.1365-2265.1987.tb01188.x

Hochberg, Z. e. (2011). Developmental Plasticity in Child Growth and Maturatiom. [Review]. Frontiers in Endocrinology, 2.

Johnson, W., Stovitz, S. D., Choh, A. C., Czerwinski, S. A., Towne, B., \& Demerath, E. W. (2012). Patterns of linear growth and skeletal maturation from birth to 18 years of age in overweight young adults. International Journal of Obesity (Lond), 36(4), 535-541. http://dx.doi.org/10.1038/ijo.2011.238

Kendal, M., \& Stuart, A. (1977). The advanced theory of statistics (4th ed. Vol. Vol.1, Distribution theory ). London: Griffin.

Lloyd, J. K., Wolff, O. H., \& Whelen, W. S. (1961). Childhood Obesity: A Long-Term Study Of Height And Weight. The British Medical Journal, 2(5245), 145-148. http://dx.doi.org/10.1136/bmj.2.5245.145

Metcalf, B. S., Hosking, J., Fremeaux, A. E., Jeffery, A. N., Voss, L. D., \& Wilkin, T. J. (2011). BMI was right all along: taller children really are fatter (implications of making childhood BMI independent of height) EarlyBird 48. International Journal Obesity (Lond), 35(4), 541-547. http://dx.doi.org/10.1038/ijo.2010.258

Murasko, J. E. (2009). Socioeconomic status, height, and obesity in children. Economics \& Human Biology, 7(3), 376-386. http://dx.doi.org/10.1016/j.ehb.2009.04.004

Murasko, J. E. (2011). Trends in the associations between family income, height and body mass index in US children and adolescents: 1971-1980 and 1999-2008. Annals of Human Biology, 38(3), 290-306. http://dx.doi.org/10.3109/03014460.2010.537698

Must, A., Jacques, P. F., Dallal, G. E., Bajema, C. J., \& Dietz, W. H. (1992). Long-term morbidity and mortality of overweight adolescents: a follow-up of the Harvard Growth Study of 1922 to 1935. New England journal of medicine, 327(19), 1350-1355. http://dx.doi.org/10.1056/NEJM199211053271904

Navti, L. K., Samani-Radia, D., \& McCarthy, H. D. (2014). Children's body fatness and prevalence of obesity in relation to height for age. Annals of Human Biology, 41(1), 84-90. http://dx.doi.org/10.3109/03014460.2013.856474

Pearce, Laura R., Atanassova, N., Banton, Matthew C., Bottomley, B., van der Klaauw, Agatha A., Revelli, J.-P., Hendricks, A., Keogh, Julia M., Henning, E., Doree, D., Jeter-Jones, S., Garg, S., Bochukova, Elena G., Bounds, R., Ashford, S., Gayton, E., Hindmarsh, Peter C., Shield, Julian P. H., Crowne, E., Barford, D., Wareham, Nick J., O’Rahilly, S., Murphy, Michael P., Powell, David R., Barroso, I., \& Farooqi, I. S. (2013). KSR2 Mutations Are Associated with Obesity, Insulin Resistance, and Impaired Cellular Fuel Oxidation. Cell, 155(4), 765-777. http://dx.doi.org/10.1016/j.cell.2013.09.058 
Ralt, D. (2007). Low muscle mass - Tall and obese children - A special genre of obesity. Medical Hypotheses, 68(4), 750-755. http://dx.doi.org/10.1016/j.mehy.2006.05.071

Reilly, J. J., \& Kelly, J. (2011). Long-term impact of overweight and obesity in childhood and adolescence on morbidity and premature mortality in adulthood: systematic review. International Journal of Obesity, 35(7), 891-898. http://dx.doi.org/10.1038/ijo.2010.222

Rolland-Cachera, M. F., Deheeger, M., Maillot, M., \& Bellisle, F. (2006). Early adiposity rebound: causes and consequences for obesity in children and adults. International Journal of Obesity, 30(S4), S11-S17. http://dx.doi.org/10.1038/sj.ijo.0803514

Rolland-Cachera, M. F., Sempé, M., Guilloud-Bataille, M., Patois, E., Péquignot-Guggenbuhl, F., \& Fautrad, V. (1982). Adiposity indices in children. The American Journal of Clinical Nutrition, 36(1), 178-184.

Sacker, A., \& Kelly, Y. J. (2012). Ethnic differences in growth in early childhood: an investigation of two potential mechanisms. The European Journal of Public Health, 22(2), 197-203. http://dx.doi.org/10.1093/eurpub/ckr032

Samani-Radia, D., \& McCarthy, H. D. (2011). Comparison of children's body fatness between two contrasting income groups: contribution of height difference. International Journal of Obesity, 35(1), 128-133. http://dx.doi.org/10.1038/ijo.2010.116

Saxena, S., Ambler, G., Cole, T. J., \& Majeed, A. (2004). Ethnic group differences in overweight and obese children and young people in England: cross sectional survey. Archives of Disease in Childhood, 89(1), 30-36.

Serdula, M. K., Ivery, D., Coates, R. J., Freedman, D. S., Williamson, D. F., \& Byers, T. (1993). Do obese children become obese adults? A review of the literature. Preventative Medicine, 22(2), 167-177. http://dx.doi.org/10.1006/pmed.1993.1014

Shrewsbury, V., \& Wardle, J. (2008). Socioeconomic Status and Adiposity in Childhood: A Systematic Review of Cross-sectional Studies 1990-2005. Obesity, 16(2), 275-284. http://dx.doi.org/10.1038/oby.2007.35

Stanojevic, S., Kain, J., \& Uauy, R. (2007). The association between changes in height and obesity in Chilean preschool children: 1996-2004. Obesity, 15(4), 1012-1022. http://dx.doi.org/10.1038/oby.2007.611

Walker, S. P., Gaskin, P. S., Powell, C. A., \& Bennett, F. I. (2002). The effects of birth weight and postnatal linear growth retardation on body mass index, fatness and fat distribution in mid and late childhood. Public Health Nutrition, 5(3), 391-396. http://dx.doi.org/10.1079/PHN2002275

Walton, S., Bedford, H., \& Dezateux, C. (2006). Use of personal child health records in the UK: findings from the millennium cohort study. BMJ, 332(7536), 269-270. http://dx.doi.org/10.1136/bmj.332.7536.269

Wardle, J., Carnell, S., Haworth, C. M. A., Farooqi, I. S., O'Rahilly, S., \& Plomin, R. (2008). Obesity Associated Genetic Variation in FTO Is Associated with Diminished Satiety. The Journal of Clinical Endocrinology \& Metabolism, 93(9), 3640-3643. http://dx.doi.org/10.1210/jc.2008-0472

Weden, M. M., Brownell, P. B., Rendall, M. S., Lau, C., Fernandes, M., \& Nazarov, Z. (2013). Parent-Reported Height and Weight as Sources of Bias in Survey Estimates of Childhood Obesity. American Journal of Epidemiology. First published online June 19th, 2013. http://dx.doi.org/10.1093/aje/kws477

Wells, J. C. (2012). The evolution of human adiposity and obesity: where did it all go wrong? Disease Models \& Mechanisms, 5(5), 595-607. http://dx.doi.org/10.1242/dmm.009613

Williams, S. M. (2005). Weight and height growth rate and the timing of adiposity rebound. Obesity Research, 13(6), 1123-1130. http://dx.doi.org/10.1038/oby.2005.131

Wolff, O. H. (1955). Obesity in Childhood. Quarterly Journal of Medicine, 24, 109. 